RA patients with low MBDA scores ( $\mathrm{N}=6$ of $16 ; 37 \%)$ but high in those with moderate/high scores ( $\mathrm{N}=10$ of $13 ; 77 \%$ ) (chi square $\mathrm{p}=0.015)$ (Figure; right graph).

Conclusions: These data show that the majority of RA patients in sustained clinical remission with low MBDA scores can successfully taper TNFi. In contrast tapering cannot be recommended in patients with moderate to high MBDA scores, as relapse rates are high in these patients.

References:

[1] Haschka J et al. Ann Rheum Dis 2016,75;45-51.

[2] Curtis JR et al. Arthritis Care Res 2012;64:1794-803.

Disclosure of Interest: None declared

DOI: 10.1136/annrheumdis-2017-eular.4787

\section{FRI0099 PAIN REDUCTION IS ASSOCIATED WITH IMPROVED WORK PRODUCTIVITY IN PATIENTS WITH RHEUMATOID ARTHRITIS}

K. Michaud ${ }^{1,2}$, B. Zhu ${ }^{3}$, C. Gaich ${ }^{3}$, A.M. DeLozier ${ }^{3}$, V. Arora ${ }^{3}$, C. Dickson ${ }^{3}$, J.S. Smolen ${ }^{4} .{ }^{1}$ University of Nebraska Medical Center, Omaha; ${ }^{2}$ NE \& National Data Bank for Rheumatic Diseases, Wichita: ${ }^{3}$ Eli Lilly and Company,

Indianapolis, United States; ${ }^{4}$ Division of Rheumatology, Medical University of Vienna, Vienna, Austria

Background: Patients with rheumatoid arthritis (RA) indicate pain is an important aspect of disease burden and may persist despite control of disease. In a randomized, double-blind phase 3 clinical trial of baricitinib (RA-BEAM), ${ }^{1}$ baricitinib provided significant improvement in pain reduction. It is not clear, however, how much reductions in pain impacted other aspects of life, such as work productivity.

Objectives: To assess the relationship between pain reduction and improvements, regardless of treatment, in daily activity and work productivity in patients with RA. Methods: In this post-hoc analysis of RA-BEAM ${ }^{1}$, pain for the intention-to-treat patients was assessed using the patient's assessment of pain $(0-100 \mathrm{~mm}$ visual analogue scale). The Work Productivity and Activity Impairment QuestionnaireRA (WPAI-RA) instrument was used to evaluate the percentage of activity impairment due to $R A$ (impairment in regular daily activities, $N=1302$ ), percentage of work-time missed due to RA (absenteeism, $\mathrm{N}=521$ ), percentage of impairment while working due to RA (presenteeism, $\mathrm{N}=490$ ), and percentage of overall work impairment due to RA (impairment in work productivity, $\mathrm{N}=490$ ). Pain was divided into pain reduction groups $(<30 \%, 30 \%-<50 \%, \geq 50 \%$ at Weeks 12 and 24 ; $\geq 30 \%[\mathrm{Y} / \mathrm{N}]$ and $\geq 50 \%[\mathrm{Y} / \mathrm{N}]$ at Weeks 1 and 2 ). Pairwise comparisons on improvement in WPAI-RA scores between pain reduction groups at Weeks 12 and 24 were assessed by ANCOVA adjusting for region, baseline joint erosion status, and baseline values of outcome variables. Missing values were imputed using the modified last-observation carried forward method.

Results: At baseline across treatment groups, the mean values ranged from 5658 for daily activity impairment, 12-13 for absenteeism, 42-46 for presenteeism, and $45-49$ for work productivity impairment. $A \geq 30 \%$ reduction in pain as early as Week 1 was associated with significantly greater $(p<0.001)$ improvement than $<30 \%$ pain reduction in regular daily activity $(-22.8$ vs -16.0$)$, presenteeism $(-17.5$ vs. -12.1$)$, and work productivity $(-16.8$ vs. -11.6$)$ at Week 12 . Greater improvement was observed in most WPAI-RA scores in patients who had more pain reduction at Weeks 12 and 24; with a reduction of $\geq 50 \%$ in pain from baseline, the WPAI-RA scores were substantially improved at Weeks 12 or 24 for daily activity, presenteeism, and work productivity (Table).

\begin{tabular}{|c|c|c|c|c|c|c|}
\hline \multirow[b]{2}{*}{ Mean (SD)\% } & \multicolumn{3}{|c|}{$\begin{array}{l}\text { Pain (VAS) \% reduction from } \\
\text { baseline at Week } 12\end{array}$} & \multicolumn{3}{|c|}{$\begin{array}{l}\text { Pain (VAS) \% reduction from } \\
\text { baseline at Week } 24\end{array}$} \\
\hline & $<30 \%$ & $\begin{array}{l}30 \%- \\
<50 \%\end{array}$ & $\geq 50 \%$ & $<30 \%$ & $\begin{array}{l}30 \%- \\
<50 \%\end{array}$ & $\geq 50 \%$ \\
\hline $\begin{array}{l}\text { Improvement in } \\
\text { WPAI-RA }\end{array}$ & \multicolumn{3}{|c|}{ WPAI-RA at Week 12} & \multicolumn{3}{|c|}{ WPAI-RA at Week 24} \\
\hline $\begin{array}{l}\text { Impairment in } \\
\text { Regular Daily Activity }\end{array}$ & $\begin{array}{c}-5.6 \\
(22.2)\end{array}$ & $\begin{array}{l}-17.8 \\
(21.8)^{\circ}\end{array}$ & $\begin{array}{l}-30.1 \\
(25.4)^{\text {cd }}\end{array}$ & $\begin{array}{c}-3.5 \\
(23.6)\end{array}$ & $\begin{array}{l}-17.1 \\
(22.4)^{\mathrm{c}}\end{array}$ & $\begin{array}{l}-33.2 \\
(25.3)^{\mathrm{ccc}}\end{array}$ \\
\hline Absenteeism & $\begin{array}{c}0.7 \\
(28.0)\end{array}$ & $\begin{array}{c}-5.2 \\
(29.7) \\
b\end{array}$ & $\begin{array}{c}-3.0 \\
(18.2)^{\mathrm{c}}\end{array}$ & $\begin{array}{c}-1.8 \\
(28.5)\end{array}$ & $\begin{array}{c}-2.1 \\
(36.1)\end{array}$ & $\begin{array}{c}-2.5 \\
(21.8)\end{array}$ \\
\hline Presenteeism & $\begin{array}{c}-2.8 \\
(24.6)\end{array}$ & $\begin{array}{c}-12.9 \\
(21.1)^{\circ}\end{array}$ & $\begin{array}{c}-23.4 \\
(24.6)^{\mathrm{cd}}\end{array}$ & $\begin{array}{c}-0.2 \\
(25.1)\end{array}$ & $\begin{array}{c}-7.7 \\
(23.1)^{\mathrm{a}}\end{array}$ & $\begin{array}{c}-26.0 \\
(25.1)^{\mathrm{cc}}\end{array}$ \\
\hline $\begin{array}{l}\text { Impairment in Work } \\
\text { Productivity }\end{array}$ & $\begin{array}{l}-2.3 \\
(24.4)\end{array}$ & $\begin{array}{l}-11.3 \\
(23.5)^{\circ}\end{array}$ & $\begin{array}{l}-23.1 \\
(26.5)^{\text {cd }}\end{array}$ & $\begin{array}{c}0.5 \\
(25.6)\end{array}$ & $\begin{array}{c}-5.7 \\
(26.2)\end{array}$ & $\begin{array}{l}-25.2 \\
(28.1)^{\mathrm{cod}}\end{array}$ \\
\hline
\end{tabular}

ip $p 0.05$; ${ }^{p} \leq \leq 0.01 ;{ }^{c} p \leq 0.001$ vs. pain reduction $<30 \%$; ${ }^{0} p<0.001$ vs. pain reduction $30-<50 \%$

Conclusions: Regardless of treatment, pain reduction was associated with improved regular daily activity and work productivity in patients with RA, with larger levels of reduction related to more improvement.

References:

[1] Taylor PC, Keystone E, van der Heijde D, et al. Baricitinib Versus Placebo or Adalimumab in Patients with Active Rheumatoid Arthritis (RA) and an Inadequate Response to Background Methotrexate Therapy: Results of a Phase 3 Study. Arthritis Rheum 2015;67(Suppl 10):3928.

Disclosure of Interest: K. Michaud Grant/research support from: Pfizer, B. Zhu Employee of: Eli Lilly and Company, C. Gaich Employee of: Eli Lilly and Company, A. DeLozier Employee of: Eli Lilly and Company, V. Arora Employee of: Eli Lilly and Company, C. Dickson Employee of: Eli Lilly and Company, J. Smolen Grant/research support from: Abbvie, Janssen, Lilly, MSD, Pfizer, Roche and has provided expert advice to and/or had speaking engagements for Abbvie, Amgen,
Astra-Zeneca, Astro, BMS, Celgene, Celltrion, Chugai, Gilead, Glaxo, ILTOO, Janssen, Lilly, Medimmune, MSD, Novartis-Sandoz, Pfizer, Roche, Samsung, Sanofi, UCB

DOI: 10.1136/annrheumdis-2017-eular.1345

\section{FRI0100 DETERMINING MINIMUM CLINICALLY IMPORTANT CHANGE IN MULTI BIOMARKER DISEASE ACTIVITY SCORE ASSOCIATED WITH CLINICAL IMPROVEMENT IN METHOTREXATE NAÏVE PATIENTS WITH EARLY RHEUMATOID ARTHRITIS}

K. Chatzidionysiou ${ }^{1}$, A.H. Hensvold ${ }^{1}$, S. Saevarsdottir ${ }^{1}$, R.J. Bolce ${ }^{2}$, D. Chernoff ${ }^{2}$, C.C. Hwang ${ }^{2}$, X. Wang ${ }^{2}$, A.I. Catrina ${ }^{1} .{ }^{1}$ Karolinska University and Institutet, Stockholm, Sweden; ${ }^{2}$ Crescendo Bioscience Inc., South San Francisco, United States

Background: The Multi-Biomarker Disease Activity (MBDA) score is a validated tool that quantifies 12 biomarkers to assess disease activity in rheumatoid arthritis (RA) patients. Many studies have demonstrated usefulness of the score for assessing RA disease activity.

Objectives: To determine minimum clinically important change in MBDA score ( $\triangle M B D A)$ from baseline (BL) to Month 3 (M3) associated with clinical improvement (decrease in DAS-ESR >1.2) in early RA patients after initiating methotrexate (MTX).

Methods: We evaluated the MBDA test in patients from one of the sites participating in the Solna Epidemiological Investigation of RA (EIRA) cohort. EIRA patients were eligible if they were $\geq 18$ years; RA diagnosis within 12 months of symptom duration; had serum and clinical assessments at BL and M3; and clinical follow-up data in the Swedish Rheumatology Quality Register. Patients naïve to disease modifying anti-rheumatic drugs who received MTX were included. Kruskal-Wallis was used to test the null hypothesis that medians of $\triangle M B D A$ scores of 3 EULAR response groups are equal. Receiver operating characteristic (ROC) analysis was performed. The optimal threshold of $\triangle M B D A$ associated with DAS28-ESR improvement (decrease in DAS-ESR $>1.2$ at M3) was determined by Youden criterion maximizing sum of sensitivity and specificity.

Results: 176 patients were included: $72 \%$ women, mean age 51 (SD: 11.7) years, mean DAS28-ESR score 5.6 (SD: 0.99); $51 \%$ had ESR $<28 \mathrm{~mm} / \mathrm{hr}, 66 \%$ were anti-CCP2+, and $22 \%$ received prednisone. Mean BL MBDA score was 56.8 (SD: 14.7) with $8(5 \%)$ patients in low $(<30), 29(16 \%)$ patients in moderate (30-44) and $139(79 \%)$ patients in high MBDA disease activity categories. Median MBDA scores for patients with no EULAR response worsened by 2 points and for patients with moderate and good response improved by 12 and 16 points, respectively $(p<0.0001$ across groups, Fig $1 A)$. Median MBDA scores improved by 10 points for all patients and 15 points in patients with a DAS28-ESR decrease $>1.2$. The best combination of sensitivity and specificity to achieve a DAS28-ESR decrease $>1.2$ was provided by $a \geq 8$ point MBDA score improvement (Fig 1B). A similar result was obtained using the bootstrap method. AUROC was 0.77 (95\% Cl: $0.71,0.84) .125$ patients $(71 \%)$ had concordance between DAS28-ESR improvement and $\triangle$ MBDA improvement at the optimal threshold (Table 1).

Table 1. Performance Measures $(95 \% \mathrm{Cl})$ Based on Optimal Threshold of $\triangle \mathrm{MBDA}$ Score from BL to M3 Associated with DAS28-ESR Improvement

\begin{tabular}{lllll}
\hline Improvement & \multicolumn{3}{c}{ DAS28-ESR (decrease $>1.2$ ) } \\
\cline { 3 - 5 } & & Yes & No & Total \\
\hline MBDA (optimal threshold: improvement $\geq 8$ points) & Yes & 75 & 27 & 102 \\
& No & 24 & 50 & 74 \\
& Total & 99 & 77 & 176 \\
\hline
\end{tabular}

Sensitivity: $0.76(0.66,0.83)$; Positive predictive value: $0.74(0.64,0.81)$; Specificity: $0.65(0.54$, 0.75); Negative predictive value: $0.68(0.56,0.77)$.r Concordance rate: $71 \%$.

Figure A) Median Change in MBDA Score by EULAR Response; B) Receiver Operating Curve (ROC) to Determine the Optimal Threshold of Change in the MBDA Score Associated with Clinical Improvement ( $\triangle D A S 28-E S R$ Decrease $>1.2$ )

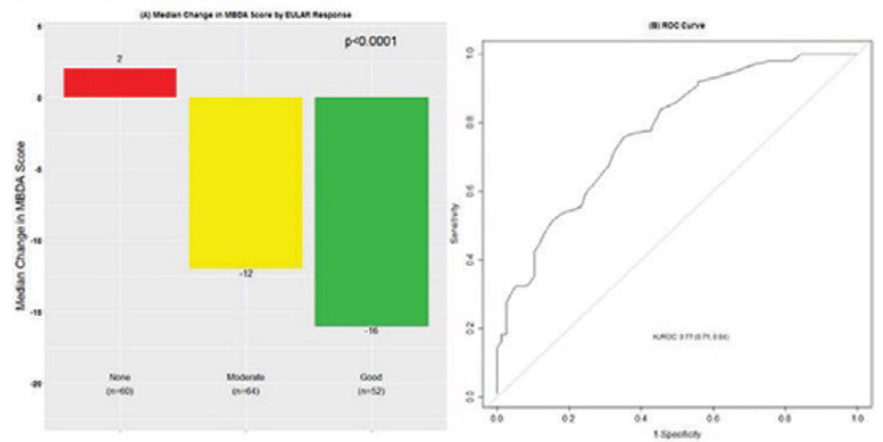

Conclusions: The optimal threshold of $\triangle \mathrm{MBDA}$ score associated with a clinically relevant decrease of DAS28 was 8 points. Using this threshold, the MBDA test is informative to detect clinical improvement. Thus, based on these results improvement in MBDA score $\geq 8$ points at M3 after initiating MTX is indicative of meaningful clinical improvement. 
Disclosure of Interest: K. Chatzidionysiou Consultant for: AbbVie, Pfizer, Eli Lilly, UCB, Roche, A. Hensvold: None declared, S. Saevarsdottir: None declared, R. Bolce Shareholder of: Myriad Genetics, Inc., Employee of: Crescendo Bioscience Inc., D. Chernoff Shareholder of: Myriad Genetics, Inc., Employee of: Crescendo Bioscience Inc., C. Hwang Shareholder of: Myriad Genetics, Inc., Employee of: Crescendo Bioscience Inc., X. Wang Shareholder of: Myriad Genetics, Inc., Employee of: Crescendo Bioscience Inc., A. Catrina Grant/research support from: Roche, Abbvie, Consultant for: BMS, GSK, Pfizer, Roche, Lilly, Abbvie DOI: 10.1136/annrheumdis-2017-eular.5534

\section{FRI0101 RA IN MALE CARPENTERS: OCCUPATIONAL WOOD DUST EXPOSURE INCREASES ACPA AND RF SEROPOSITIVITY AND SIGNIFICANTLY RAISES RF TITRES}

K. Bellis ${ }^{1}$, M. Whallett ${ }^{2}$, D. Murphy ${ }^{1,2}$, D. Hutchinson ${ }^{1,2} \cdot{ }^{1}$ Rheumatology, Royal Cornwall Hospital; ${ }^{2}$ University of Exeter Medical School, Cornwall Campus, Truro, Cornwall, United Kingdom

Background: Wood dust has been hypothesised as a trigger in RA. Exposure may activate peptidyl arginine deaminase through exposure to silica and carbon nanoparticles, ${ }^{1}$ stimulating RF autoantibody production. ${ }^{2}$ Though non-silica dusts have shown increased RA risk in construction workers, wood dust exposed individuals were excluded from analysis in a recent large registry study. ${ }^{3}$

Objectives: To analyse the autoantibody status of male RA wood workers in Cornwall, UK, compared to matched RA controls with no occupational dust or fume exposure.

Methods: All male RA patients were sent an occupational questionnaire, detailing current occupation, last occupation (if retired) and other occupations for $>1$ year. Telephone follow up was completed to minimise missing data. 41/720 (6\%) patients died during the study period (22 months). 39/720 (5\%) were excluded due to incomplete data. $147 / 640(23 \%)$ had exposure to wood dust including other dust co-exposures, with $44 / 147(30 \%)$ indentifying wood dust as their primary occupational exposure as carpenters, approximately seven times higher than expected given UK employment census data. This cohort was matched to 102 RA controls with no dust or fume exposure for age $+/-5$ years, sex and index of multiple deprivation (IMD) $+/-1$ decile. RF titres were compared via 2 tailed Mann Whitney $U$ test, and ACPA seropositivity was compared using a $Z$ test of 2 proportions.

Results: No significant differences were seen in median age between woodworker cases (median 59 years IQR 50-63), and controls (median 58 years IQR 48-65). Woodworker never smokers demonstrated significantly higher seropositivity rates for both RF and ACPA than respective controls, and RF titres were significantly higher amongst woodworkers irrespective of smoking (Table 1). Median smoking rates were not significantly different between cohorts: woodworkers median pack years 23.5 (IQR 14.75-36), control median pack years 20.5 (IQR 10.25-32.75).

Table 1. Seropositivity rates and RF levels for woodworkers vs. controls

\begin{tabular}{|c|c|c|}
\hline & Median RF (IQR) & $\mathrm{ACPA}+(\%)$ \\
\hline Control never smokers $(n=40)$ & $16(\text { IQR } 6.7-47.2)^{\star}$ & $19 / 40(48 \%)^{\star \star \star}$ \\
\hline Control ever smokers $(n=62)$ & $68.9(\text { IQR } 20.65-167.58)^{\star \star}$ & $46 / 62(74 \%)^{\star \star \star \star}$ \\
\hline Wood worker never smokers $(n=8)$ & $86.4($ IQR 19.5-230.3)* & $7 / 8(88 \%)^{\star \star \star}$ \\
\hline Wood worker ever smokers $(n=36)$ & $156.1(\text { IQR } 54-321.1)^{\star \star}$ & $29 / 36(81 \%)^{\star \star \star \star}$ \\
\hline
\end{tabular}

${ }^{\star} \mathrm{p}<0.04 ;{ }^{* \star} \mathrm{p}<0.01 ;{ }^{* \star \star} \mathrm{p}<0.04 ;{ }^{* \star \star} \mathrm{p}=$ not sig.

Conclusions: Wood dust exposed RA patients are more likely to be seropositive. Sequential environmental insults of smoking and wood dust exposure have an additive effect on rheumatoid factor levels, conferring increased disease severity. Further studies are needed to determine if occupational wood dust exposure causes RA.

References:

[1] Murphy D, Sinha A, Hutchinson D. Wood Dust: A Trigger for Rheumatoid Arthritis? Am J Med 2015;128:e35.

[2] Hubbard R, Lewis S, Richards K, Johnston I, Britton J. Occupational exposure to metal or wood dust and aetiology of cryptogenic fibrosing alveolitis. Lancet 1996;347:284-9.

[3] Blanc PD, Jarvholm B, Toren K. Prospective risk of rheumatologic disease associated with occupational exposure in a cohort of male construction workers. Am J Med 2015;128:1094-101.

Acknowledgements: Cornwall Arthritis Trust

Disclosure of Interest: None declared

DOI: 10.1136/annrheumdis-2017-eular.3733

\section{FRI0102 ULTRASOUND AND MRI DURING FLARES OF PALINDROMIC RHEUMATISM REVEAL A DISTINCT PHENOTYPE EVEN IN IMMINENT RA}

K. Mankia ${ }^{1}$, M.-A. D'Agostino ${ }^{1}$, R. Wakefield ${ }^{1}$, G. Eugenio ${ }^{1}$, L. Horton ${ }^{1}$, J. Nam ${ }^{1}$, A. Grainger ${ }^{2}$, P. Emery ${ }^{1} .{ }^{1}$ Leeds Institute of Rheumatic and Musculoskeletal Medicine and Nihr Leeds Musculoskeletal Biomedical Research Unit; ${ }^{2}$ Radiology, Leeds Teaching Hospitals NHS Trust, Leeds, United Kingdom

Background: Palindromic rheumatism $(\mathrm{PR})$ is a recurrent, self-abortive arthritis and/or peri-arthritis which progresses to RA in up to $50 \%$ of patients, especially those that are anti-CCP positive (1). Whether PR is truly a prodrome of RA or a distinct syndrome is unclear; the pathological phenotype of PR flare, and whether this changes when RA is imminent, remains unknown

Objectives: To describe the clinical and imaging (US and MRI) phenotype during PR flares and to determine whether this changes in PR patients with imminent RA. We hypothesised PR patients with imminent RA would have a RA phenotype during flare

Methods: Patients were recruited from a prospective PR cohort. PR flares were defined as $\geq 2$ of pain, swelling, erythema in or around $\geq 1$ joint, that later normalised. Clinical details were recorded during flares. Blinded US assessment (wrists, MCPs, PIPs, elbows, knees, MTPs, ECUs and 2nd-5th finger flexor tendons) was performed during and between flares. Synovitis, tenosynovitis, subcutaneous oedema, peri-articular inflammation and peri-tendinous oedema were reported at each joint. Where possible, MRI was also performed on the most symptomatic region during flare. Patients were followed for progression to RA Results: US was performed in 22 patients during flare. 19 patients also had non-flare US. Mean age was 49 yrs. 16/22 (73\%) were anti-CCP+ and 6/22 (27\%) anti-CCP-. Six (27\%) patients developed RA (mean 23 weeks post flare); these patients had higher frequency of flares and absence of flare trigger (figure) but no difference in distribution of flaring joints. The flare US showed grey scale (GS) synovitis in 13/22 (59\%) patients, power Doppler (PD) synovitis in 4/22 (18\%) and no erosions. 12/22 (55\%) patients had peri-articular inflammation and/or subcutaneous oedema; in 6 patients this was without synovitis/tenosynovitis. Tenosynovitis and/or peri-tendinous oedema were present in 6/22 (27\%) patients. Non-flare US demonstrated fewer abnormalities with improvement post flare. In 5 patients multiple flares were imaged with variable US abnormalities identified. The US flare phenotype did not differ (from non-progressors) in patients who progressed to RA, with PD synovitis present in only $17 \%$ (table 1) contrasting with our early RA cohort where PD synovitis occurred in $73 \%$ of patients (2). MRI was performed on 8 patients ( 2 flares imaged in 1 patient) and detected more pathology than US. Bone marrow oedema (BME) was found in only 1 patient. No erosions were seen.

Table 1

\begin{tabular}{lcc}
\hline US abnormality & Progressed to RA $(\mathrm{n}=6)$ & Not progressed to RA $(\mathrm{n}=16)$ \\
\hline PD synovitis & $1(17 \%)$ & $3(19 \%)$ \\
GS synovitis & $2(33 \%)$ & $10(63 \%)$ \\
Tenosynovitis & $1(17 \%)$ & $4(25 \%)$ \\
Peri-tendinous oedema & $0(0 \%)$ & $2(13 \%)$ \\
Peri-articular inflammation & $1(17 \%)$ & $7(44 \%)$ \\
Subcutaneous oedema & $3(50 \%)$ & $6(38 \%)$ \\
\hline
\end{tabular}

\begin{tabular}{|c|c|c|c|}
\hline & & $\begin{array}{c}\text { Progressed to RA } \\
(n=6)\end{array}$ & $\begin{array}{c}\text { Not progressed to } \\
\text { RA }(n=16)\end{array}$ \\
\hline \multicolumn{2}{|l|}{ Anti-CCP positive } & $5(83 \%)$ & $11(69 \%)$ \\
\hline \multicolumn{2}{|c|}{ Disease duration (yrs), median (IQR) } & $2.6(1.8-9.2)$ & $3.1(1.1-7.4)$ \\
\hline \multicolumn{2}{|c|}{ Frequency of flares (per yr), median (IQR) } & $25(12-50)$ & $9(5-23)$ \\
\hline \multicolumn{2}{|c|}{ Flare Trigger identifiable? } & $0(0 \%)$ & $7(44 \%)$ \\
\hline & Mechanical & $0(0 \%)$ & $4(57 \%)$ \\
\hline & Emotional Stress & $0(0 \%)$ & $3(43 \%)$ \\
\hline \multicolumn{4}{|l|}{ Flare symptoms } \\
\hline & Joint pain & $6(100 \%)$ & $15(94 \%)$ \\
\hline & Joint swelling & $5(83 \%)$ & $15(94 \%)$ \\
\hline & Skin colour change & $6(100 \%)$ & $14(88 \%)$ \\
\hline \multicolumn{2}{|c|}{ Number of joints involved in the flare, median (IQR) } & $2(1-5)$ & $2(1-4)$ \\
\hline \multicolumn{2}{|c|}{ CRP (mg/L), median (IQR) } & $10.8(6.0-31)$ & $9.0(2.2-41.3)$ \\
\hline
\end{tabular}

Conclusions: PR flares have a distinct imaging phenotype characterised by peri-articular inflammation and subcutaneous oedema, often without synovitis. The low prevalence of PD synovitis, BME and erosions distinguishes PR from RA. PR patients with imminent RA have no triggers and more frequent flares, but retain the distinct $P R$ phenotype. This suggests distinct pathological mechanisms in PR and should be of value for potential therapeutic interventions.

References:

[1] Russell AS et al.J Rheumatol 2006.33(7):1240-2.

[2] Horton SC et al.Rheumatol 2016;55:1177-87.

Disclosure of Interest: None declared

DOI: 10.1136/annrheumdis-2017-eular.6237

\section{FRI0103 CONTRIBUTION OF SUBJECTIVE DISEASE ACTIVITY SCORE 28 (DAS28) COMPONENTS TO THE RESPONSE TO TREATMENT OF RHEUMATOID ARTHRITIS}

K.M. Son ${ }^{1}$, S.Y. Lee ${ }^{2}$, Y.I. Seo ${ }^{2}$, J.-E. Choi ${ }^{3}$, H.A. Kim ${ }^{2} .{ }^{1}$ Hallym University Dongtan Sacred Heart Hospital; ${ }^{2}$ Hallym University Sacred Heart Hospital, Gyeonggi-Do; ${ }^{3}$ Ewha womans University, Seoul, Korea, Republic Of

Background: Some patients with rheumatoid arthritis (RA) do not respond adequately to treatment.

Objectives: We investigated the contributions made by the subjective components of the disease activity score 28 (DAS28) to the treatment response of RA. In addition, factors associated with poor response to treatment at 6 months, despite normalization of objective measures, were examined. 